\title{
HrpS Is a Global Regulator on Type III Secretion System (T3SS) and Non-T3SS Genes in Pseudomonas savastanoi pv. phaseolicola
}

\author{
Jingru Wang, ${ }^{1}$ Xiaolong Shao, ${ }^{1}$ Yingchao Zhang, ${ }^{1}$ Yanan Zhu, ${ }^{2}$ Pan Yang, ${ }^{1}$ Jian Yuan, ${ }^{1}$ Tingting Wang, ${ }^{3}$ \\ Chunyan Yin, ${ }^{1}$ Wei Wang, ${ }^{1}$ Sheng Chen, ${ }^{4}$ Haihua Liang, ${ }^{5,+}$ and Xin Deng ${ }^{3,+}$ \\ ${ }^{1}$ Key Laboratory of Molecular Microbiology and Technology, Ministry of Education, TEDA Institute of Biological Sciences and \\ Biotechnology, Nankai University, 23 Hongda Street, Tianjin, 300457, China; ${ }^{2}$ Department of Biochemistry and Molecular \\ Biology, University of Georgia, Athens, GA, U.S.A.; ${ }^{3}$ Department of Biomedical Sciences, City University of Hong Kong, 83 Tat \\ Chee Rd, Kowloon Tong, Hong Kong; ${ }^{4}$ Department of Applied Biology and Chemical Technology, The Hong Kong Polytechnic \\ University, Hung Hom, Hong Kong; and ${ }^{5}$ Key Laboratory of Resources Biology and Biotechnology in Western China, Ministry of \\ Education, College of Life Science, Northwest University, Xi'an, ShaanXi 710069, China
}

Accepted 12 April 2018.

\begin{abstract}
The type III secretion system (T3SS) is the main machinery for Pseudomonas savastanoi and other gram-negative bacteria to invade plant cells. HrpR and HrpS form a hetero-hexamer, which activates the expression of HrpL, which induces all T3SS genes by binding to a ' $h r p$ box' in promoters. However, the individual molecular mechanism of HrpR or HrpS has not been fully understood. Through chromatin immunoprecipitation coupled to high-throughput DNA sequencing, we found that HrpR, HrpS, and HrpL had four, 47, and 31 targets on the genome, respectively. HrpS directly bound to the promoter regions of a group of T3SS genes and non-T3SS genes. HrpS independently regulated these genes in a $h r p L$ deletion strain. Additionally, a HrpS-binding motif (GTGCCAAA) was identified, which was verified by electrophoretic mobility shift assay and $l u x$-reporter assay. $\mathrm{HrpS}$ also regulated motility and biofilm formation in $P$. savastanoi. The present study strongly suggests that HrpS alone can work as a global regulator on both T3SS and non-T3SS genes in $P$. savastanoi.
\end{abstract}

Pseudomonas savastanoi and other gram-negative pathogenic bacteria infect host organisms via the needle-like type III secretion system (T3SS) (Galán and Collmer 1999). T3SS in

Jingru Wang and Xiaolong Shao contributed equally to the paper as first authors.

Sequencing data is available in the National Center for Biotechnology Information database under accession number GSE103921.

${ }^{\dagger}$ Corresponding authors: Xin Deng; E-mail: xindeng@cityu.edu.hk and Haihua Liang; E-mail: lianghh@nwu.edu.cn

Funding: This work was supported by National Natural Science Foundation of China (31670127), Tianjin Natural Science Foundation (17JCYBJC23800), Health and Medical Research Fund of Hong Kong (17160022), and City University of Hong Kong Grants (7200535 and 9610370). The funders had no role in study design, data collection and analysis, decision to publish, or preparation of the manuscript

*The $\boldsymbol{e}$-Xtra logo stands for "electronic extra" and indicates that nine supplementary figures and four supplementary tables are published online.

(c) (i) (5) $\odot$ Copyright $(9) 2018$ The Author(s). This is an open access article distributed under the CC BY-NC-ND 4.0 International license.
P. savastanoi includes a hrp (hypersensitive response and pathogenicity) pilus and inner and outer membrane rings (Kubori et al. 1998; Roine et al. 1997). In P. savastanoi, T3SS is encoded by the $h r p$ genes, hypersensitive response conserved ( $h r c)$ genes, avirulence (avr) genes, and $h r p$-dependent outer protein ( $h o p$ ) genes (Alfano et al. 1997). The T3SS leads to disease development in host plants and hypersensitive response in nonhost (Collmer et al. 2000) and resistant plants. The expression of T3SS genes is repressed in nutrient-rich media (King's B broth [KB]), while it is activated in minimal medium (MM) and plants (Xiao et al. 2007).

HrpL, an alternative sigma factor, is a key T3SS activator by recognizing a ' $h r p$ box' (5'-GGAACC-N(15-16)-CCACNNA$3^{\prime}$ ) in promoters of T3SS genes (Lindeberg et al. 2005; Nissan et al. 2005). Under T3SS-inducing conditions, the transcription of $h r p L$ is activated by HrpR and HrpS, which form a heterohexamer (Xiao et al. 1994). RpoN $\left(\sigma^{54}\right)$ is also required for the induction of hrpL (Lindeberg et al. 2006; Nissan et al. 2005). HrpS independently induces $h r p L$ transcription, which can be maximized by HrpRS (Hutcheson et al. 2001). HrpRS binds to a 47-bp region (101 to $147 \mathrm{bp}$ upstream of ATG) in the $h r p L$ promoter in P. savastanoi pv. tomato DC3000 (Jovanovic et al. 2011); however, the precise binding motif is unclear. HrpL is negatively autoregulated, which fine-tunes the expression of T3SS (Waite et al. 2017).

HrpR and HrpS are the bacterial enhancer-binding proteins and ATPases associated with various cellular activities (AAA+) (Morett and Segovia 1993; Schumacher et al. 2006). Previous studies have characterized their secondary structures, including the AAA+ domain (containing regions for ATP-binding, $\sigma^{54}$ binding, nucleotide hydrolysis, inter-subunit catalysis, and nucleotide-dependent oligomerization) and the DNA binding domain (helix-turn-helix structure in C-terminal) (Jovanovic et al. 2011; Lawton et al. 2014). Three residues in HrpR (D32, D34, E202, and K235) and three in HrpS (D32, G30, E200, and $\mathrm{K} 233$ ) are keys in the self-association process (Lawton et al. 2014). HrpR-D32 and HrpS-K233 residues are crucial to the formation of HrpRS hetero-hexamer (Lawton et al. 2014). In Erwinia amylovora, there is only one $h r p S$ gene, which is evolved to homologous $h r p R$ and $h r p S$ via gene duplication in P. savastanoi (Vencato et al. 2006b).

HrpV acts as an inhibitor of T3SS by directly binding to HrpS (Preston et al. 1998). The inhibition of HrpS by HrpV can be released by a chaperone-like protein HrpG (Wei et al. 2005). 
L108, A109, and G110 of HrpV are the critical sites for the interactions with HrpS and HrpG, while F6, L101, and L105 of $\mathrm{HrpG}$ are the keys for direct interaction with HrpV (Jovanovic et al. 2017). In addition, another T3SS inhibitor, Lon, an ATPdependent protease, directly degrades HrpR to negatively regulate the repression of T3SS genes (Bretz et al. 2002). Our previous work shows that a two-component system response regulator,
RhpR, directly binds to the $h r p R$ promoter by recognizing a putative IR motif (ATTTC-N 6 -GATAC) (Deng et al. 2010, 2014). AefR, the key regulator of quorum sensing in $P$. savastanoi (Quiñones et al. 2004), also positively regulates $h r p R$ (Deng et al. 2009).

Although the HrpRSL regulatory cascade has been characterized previously, the comprehensive profiling and individual
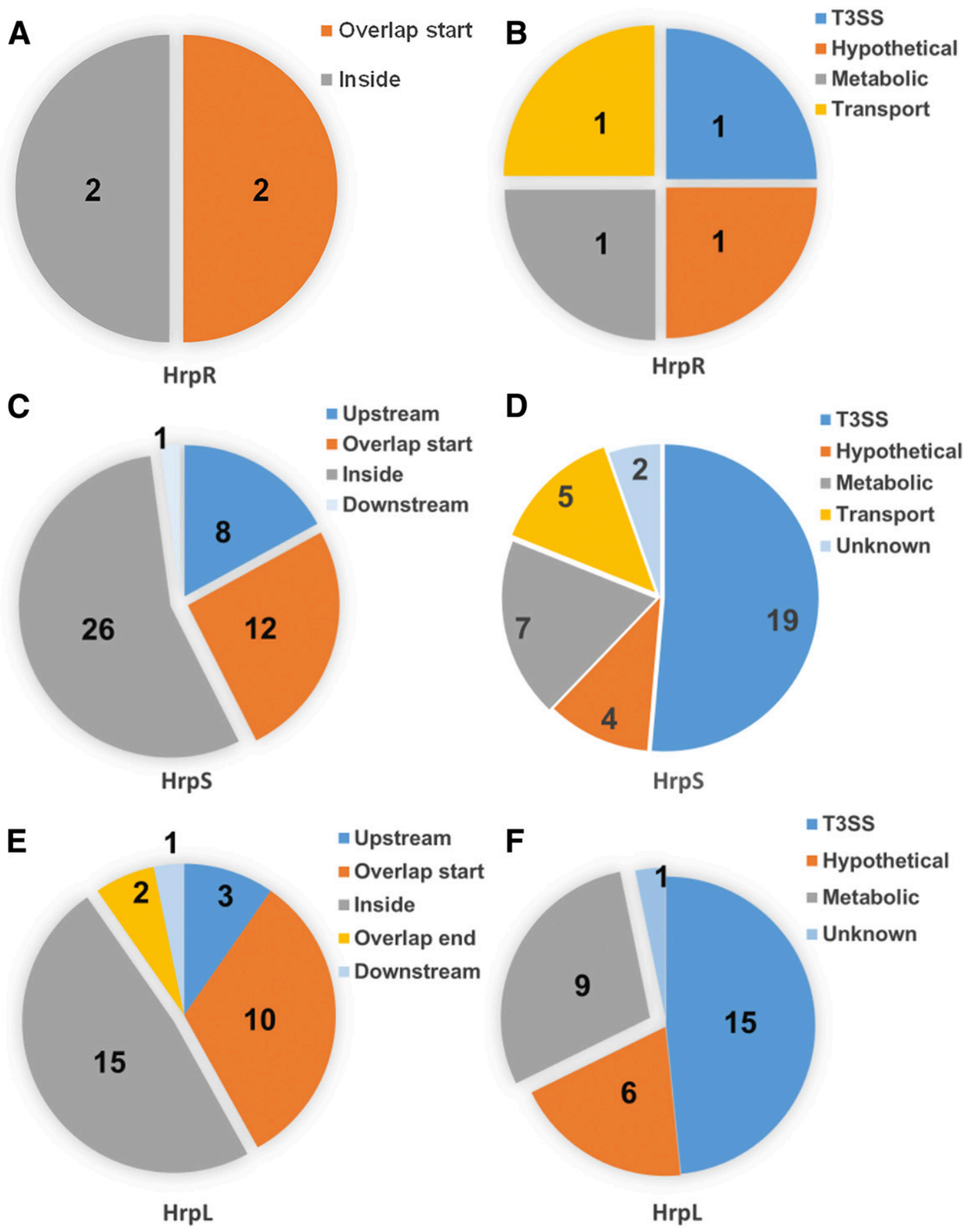

Fig. 1. Chromatin immunoprecipitation coupled to high-throughput DNA sequencing revealed in vivo binding sites of HrpS, HrpR, and HrpL in the Pseudomonas savastanoi genome. A, In HrpR-binding peaks, two loci were detected within coding regions and two in the overlap start region. B, The functions of HrpR-binding genes were diverse, including metabolism (1), type III secretion system (T3SS) (1), transport (1), and hypothetical proteins (1). C, In HrpSbinding peaks, 47 loci are distributed throughout the genome in intergenic regions (21) and coding regions (26). Notably, 20 peaks were located upstream of genes or overlapped with the promoter regions. D, The HrpS-bound genes encode proteins with diverse functions, including T3SS (19), metabolism (7), transport (5), hypothetical proteins (4), and unknown functions (2). E, Among 31 loci in the HrpL-binding peaks, 13 binding to the upstream or overlap starting region, 15 in inside region, two in overlap the end, and one in the downstream. F, The functions of HrpL-binding genes can be evenly classified into T3SS (15), metabolism (9), hypothetical proteins (6) and unknown (1). 
characterization of HrpR or HrpS have yet to be carried out. In the present study, chromatin immunoprecipitation coupled to highthroughput DNA sequencing (ChIP-seq) was used to identify all direct binding loci of HrpR, HrpS, or HrpL. HrpS not only functions as an independent regulator to activate a group of T3SS but also control several non-T3SS genes in $P$. savastanoi. A specific HrpS-binding motif (GTGCCAAA) is identified in the $h r p L$ promoter. The results show that HrpS directly regulates a group of downstream genes, which is independent on HrpL. The present study brings novel insights into the molecular regulatory mechanism of T3SS regulatory cascade.

\section{RESULTS}

\section{Genome-wide ChIP-seq analyses}

of HrpR, HrpS, and HrpL-binding regions.

HrpR and HrpS share the same upstream promoter and work as hetero-hexamer to activate the expression of the $h r p L$ gene (Hutcheson et al. 2001). To comprehensively elucidate the direct targets of HrpR, HrpS, and HrpL, we mapped their binding loci on the chromosome of Pseudomonas savastanoi pv. phaseolicola 1448A, using the ChIP-seq assays in MM (Blasco et al. 2012). The FLAG-tagged HrpR, HrpS, or HrpL full length were respectively expressed under their own promoters in a lowcopy pHM2 vector in the wild-type strain in MM. Each sequence

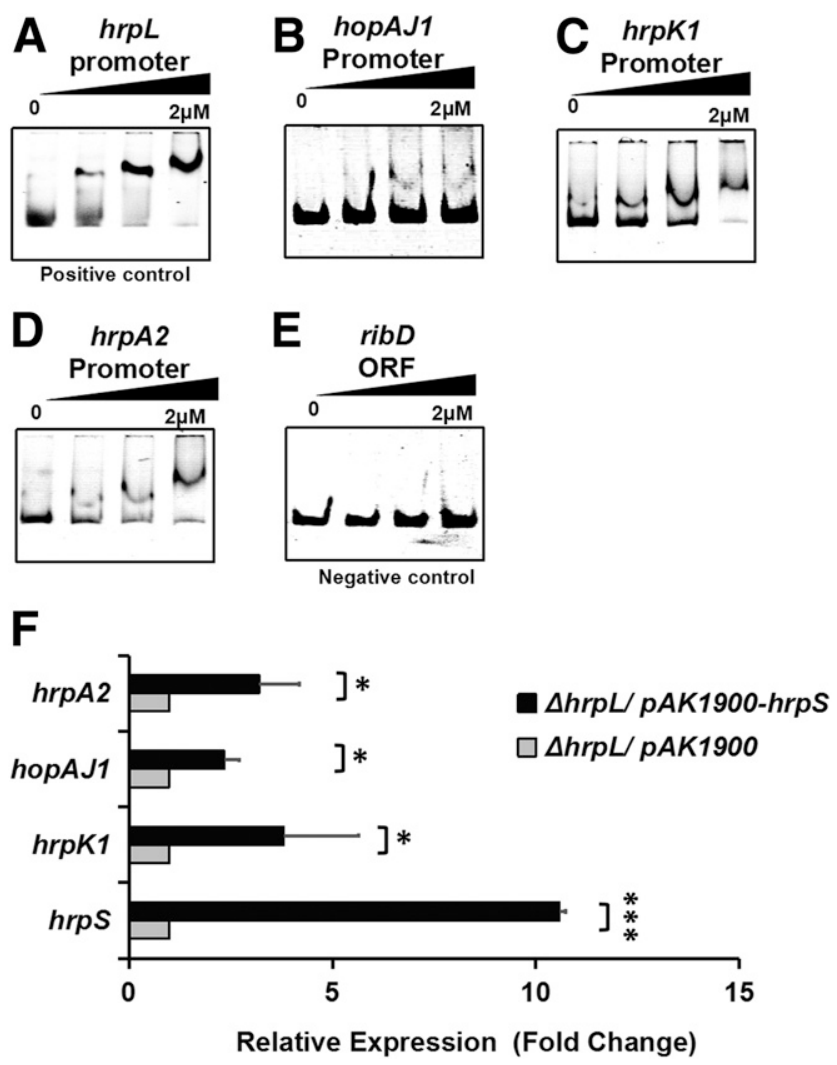

Fig. 2. HrpS directly bound to a group of type III secretion system genes. A, HrpSC showed the maximal binding affinity with the hrpL promoter. Different concentrations of $\operatorname{HrpS}(0,0.5,1.0$, and $2.0 \mu \mathrm{M})$ were mixed with 40 ng DNA fragments. B to D, HrpS bound to the promoters of hrpK1, hrpA2, and hopAJ1. E, HrpSC did not bind to negative control ribD at the same protein concentrations. F, Quantitative reverse transcription-polymerase chain reaction (RT-qPCR) revealed that HrpS independently activated hrpK1, hrpA2, and hopAJ1. pAK1900-hrpS or pAK1900 empty vector were transformed into the $P$. savastanoi pv. phaseolicola $\Delta \mathrm{hrpL}$ strain. RTqPCR was performed to measure the transcription level of hrpL, hrpK1, hrpA2, and hopAJ1 in both strains. One asterisk (*) denotes $P<0.05$ and three $(* * *)$ denote $P<0.001$ compared with hrpL, by Student's $t$ test. Each experiment has been performed three times. data was obtained from two independent ChIP-seq assays using FLAG-specific antibody and were subsequently mapped to the $P$. savastanoi pv. phaseolicola genome. Using the MACS software (Zhang et al. 2008), we identified four, 47, and 31 enriched loci $(P$ value $=\mathrm{E}-5)$ harboring HrpR, HrpS, or HrpL-binding peaks, respectively, which were enriched but were absent in control samples using wild-type $P$. savastanoi pv. phaseolicola without a FLAG tag (Supplementary Table S1).

Only four loci were identified in the HrpR-binding peaks, including two that were located in intergenic regions; the other two were in coding regions (Fig. 1A). They encode proteins associated with metabolism, T3SS, and transposition (Fig. 1B). In the HrpS-binding peaks, 47 loci were distributed throughout the genome in both intergenic regions (21 loci, 43\%) and coding regions (26 loci) (Fig. 1C). Like HrpR, the HrpS-binding genes encode proteins associated with T3SS (19 genes), metabolism (seven genes), and transposition (five genes) (Fig. 1D). Among 31 loci in the HrpL-binding peaks, 13 were located in intergenic regions (Fig. 1E).

HrpR bound to a group of non-T3SS genes (PSPPH_2426, PSPPH_2767, ribD), which encode proteins associated with riboflavin biosynthesis, regulation, and transport. Interestingly, two non-T3SS genes (PSPPH_1525 and PSPPH_1855) and a group of T3SS genes, such as the hrpA2-hrpZ1-hrpB-hrcJ-hrpD$h r p E-h r p F$ operon, the $h r c V$-hrpQ-hrcN-hrpO-hrpP-hrcQa-hrcQbhrcR-hrcS-hrcT-hrcU operon, hopIl, hrpWl, hrpJ, hrpL, hrpK1, and hopX1, were shared between HrpS-binding loci and HrpL-binding loci (Supplementary Fig. S1).

\section{HrpS directly binds to a group of T3SS genes.}

Since HrpS had more binding loci than HrpL, we hypothesized that HrpS alone has profound regulatory functions on T3SS and non-T3SS genes, which is tested in the following experiments. First, to verify the direct interaction between HrpS and its binding loci, we purified the full-length HrpS in Escherichia coli and then performed an electrophoretic mobility shift assay (EMSA). The hrpL promoter was used as a positive control (Hutcheson et al. 2001; Jovanovic et al. 2011). As a result, the full-length HrpS protein had low yield and low binding affinity with the promoter regions of $h r p L, h r p K l$, hrpA2, and hopAJ1. However, a recent study in Erwinia amylovora obtained optimal DNA-binding affinity of HrpS by expressing the C-terminal DNA-binding domain (Lee et al. 2016). Inspired by this work, a truncated HrpS containing the DNA-binding domain (amino acids 235 to 302, designated as $\mathrm{HrpS}^{\mathrm{C}}$ ) was cloned into pET28a. We successfully purified $\mathrm{HrpS}^{\mathrm{C}}$ protein (Supplementary Fig. S2), which showed significantly improved binding affinity with the $h r p L$ promoter (Fig. $2 \mathrm{~A}) . \mathrm{HrpS}^{\mathrm{C}}$ bound to the promoters of $h r p K 1, h r p A 2$, and hopAJ1 (Fig. 2B to D), compared with the negative control ribD at the same protein concentration (Fig. 2E). These results suggested that HrpS directly regulates the transcription of hrpK1, hrpA2 and hopAJ1.

\section{HrpS activates a group of T3SS genes that are independent of HrpL.}

Since $\operatorname{HrpS}^{\mathrm{C}}$ directly bound to hrpK1, hrpA2, and hopAJ1, we then attempted to test if $\mathrm{HrpS}$ alone can activate these three genes in vivo, via quantitative reverse transcription-polymerase chain reaction (RT-qPCR). To avoid the induction of T3SS genes via HrpL, we compared the transcription level of these three T3SS genes between a $\Delta h r p L$ mutant containing pAK1900$h r p S$ overexpressing (10-fold) the full-length HrpS protein and a $\triangle h r p L$ strain containing the empty vector pAK1900 (Fig. 2F). The levels of $h r p K 1, h r p A 2$, and $h o p A J 1$ were induced fourfold by $\operatorname{HrpS}$ (Fig. 2F), suggesting that HrpS positively regulates them. 
To further verify this result in vivo, a lux-reporter assay in MM was used to measure the activity of these three promoters by cloning their promoter regions into pMS402 plasmid. The promoter-lux reporters and pAK1900-hrpS were cotransformed into the $P$. savastanoi pv. phaseolicola $\Delta h r p L$ strain, while the empty pAK1900 was cotransformed with the promoter-lux reporters into the $\Delta h r p L$ mutant as a control. As expected, the activities of all tested promoters were significantly induced by overexpression of HrpS (Fig. 3A to C). As a positive control, hrpL-lux was induced dramatically by HrpS in the $\Delta h r p L$ mutant (Fig. 3D). These results indicate that HrpS directly activates the transcription of $h r p K 1, h r p A 2$, and hopAJ1, which are not dependent on HrpL.

\section{A specific 8-bp motif (GTGCCAAA)}

in the $h r p L$ promoter is essential for HrpS activation.

Although the interaction between $\mathrm{HrpR} / \mathrm{HrpS}$ and the $h r p L$ promoter has been well documented, the exact binding motif is still elusive. We attempted to use $\mathrm{HrpS}^{\mathrm{C}}$ to pinpoint the HrpSbinding motif on the $h r p L$ promoter. First, we truncated the hrpL promoter into different lengths (full-length, 242, 200, 191, $185,175,165,158,150,143$, and 128 bp from ATG) with the same 3' end (Supplementary Table S2). Subsequently, EMSA were performed to detect the binding regions of $\mathrm{HrpS}^{C}$ in these truncated $h r p L$ promoters. $\operatorname{HrpS}^{\mathrm{C}}$ showed obvious binding shift on the $h r p L$ promoter truncations longer than 165 bp (Fig. 4A to $\mathrm{F})$, while there was no binding shift when the truncations were shorter than 158 bp (Fig. 4G to J). We used the promoter of the gene pepA encoding leucyl aminopeptidase as a negative control, as it was absent in our ChIP-seq results (Fig. 4K). Therefore, we speculated that the HrpS-binding motif in the hrpL promoter is located in a specific sequence from -165 to -150 bp (Fig. 4L).
Previous studies show that the HrpS/HrpR hetero-hexamer binds to an 8-bp region in the hrpL promoter (from -146 to -139 bp) in P. savastanoi pv. tomato DC3000 (Jovanovic et al. 2011; Waite et al. 2017). A similar sequence was found from -161 to -153 bp (GTGCCAAA) in the $h r p L$ promoter in P. savastanoi pv. phaseolicola (Supplementary Fig. S3), which suggests HrpS specifically binds to this motif. In order to verify and characterize this putative motif, we made 18-point mutants carrying single substitutions (A169C, G165A, T164C, T163C, T162C, G161A, T160C, G159T, C158T, C157A, A156C, $\mathrm{A} 155 \mathrm{C}, \mathrm{A} 154 \mathrm{C}$, or A153C), deletions (160D or 158D), or insertions (159I1 or 159I2) in the 171-bp hrpL promoter. EMSA were performed using the wild-type 165-bp $h r p L$ promoter as the positive control and the pepA promoter as the negative control (Fig. 5A and B). Intriguingly, $\mathrm{HrpS}^{\mathrm{C}}$ bound to probes carrying mutants between -165 to -162 bp (G165A, T164C, T163C, and T162C) (Supplementary Fig. S4) but did not bind to the probes carrying mutants ranged from -161 to $-154 \mathrm{bp}$ (G161A, T160C, G159T, C158T, C157A, A156C, A155C, and A154C) (Fig. 5C to G). In addition, the probes carrying deletions or insertions (deletion 160D or 158D, insertion 159I1 or 159I2) also compromised the binding affinity with $\operatorname{HrpS}^{\mathrm{C}}$ (Fig. $5 \mathrm{~L}$ to $\mathrm{O})$. The promoter of $h r p L$ with point mutations upstream of the $-161 \mathrm{bp}$ or downstream of $-154 \mathrm{bp}$ (A169C and A153C) retained binding shifts with $\mathrm{HrpS}^{\mathrm{C}}$ (Fig. 5K). Taken together, the EMSA demonstrated that the 8-bp sequence (GTGCCAAA, from -161 to $-153 \mathrm{bp}$ ) is essential for HrpS binding.

161G, 159G, and 157C are crucial sites in HrpS-binding motif.

To provide further evidence to evaluate the importance of HrpS-binding motif in vivo, we measured the activities of a
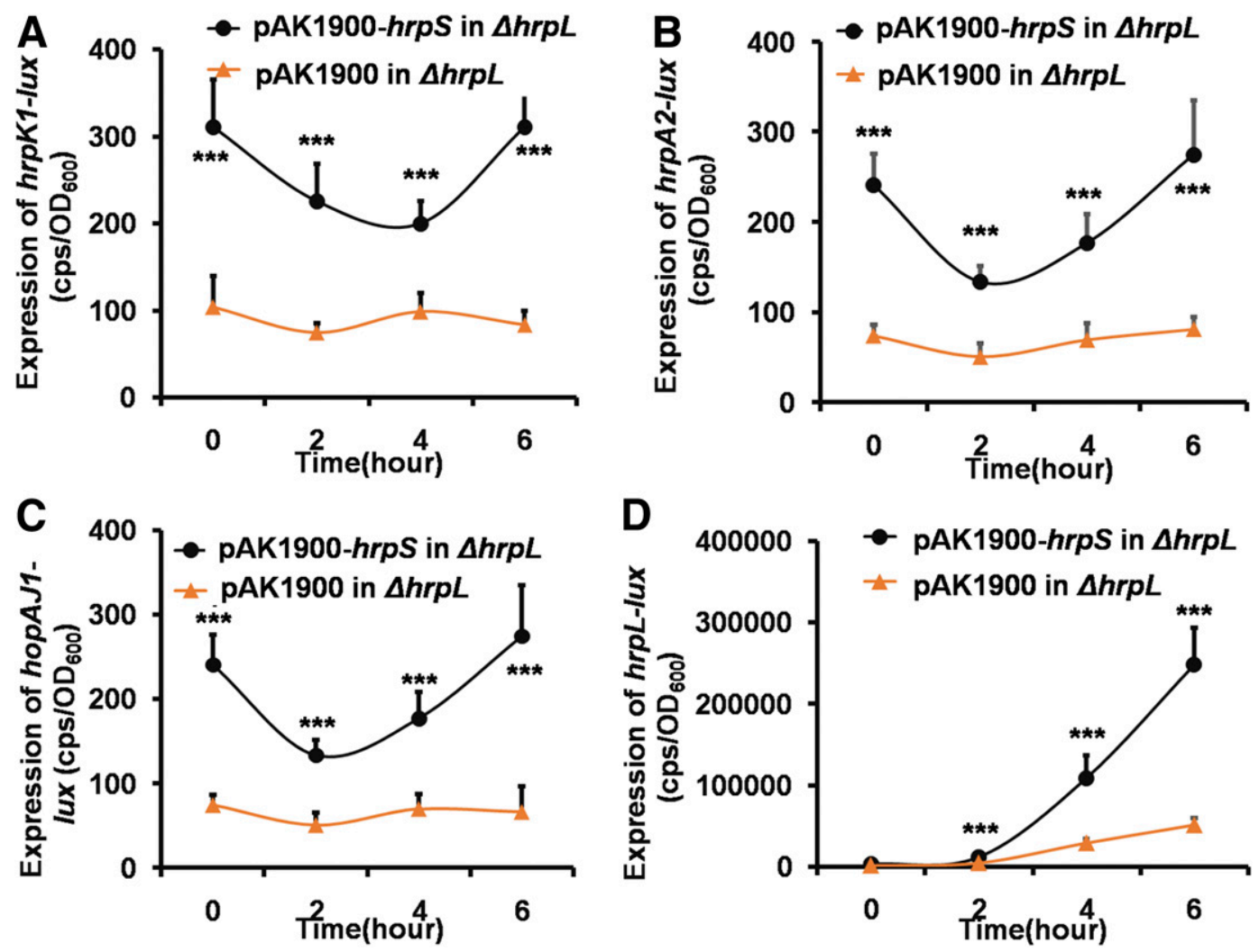

Fig. 3. HrpS directly activated the expression of hrpA2, hrpK1, and hopAJ1 in vivo. pAK1900-hrpS/pAK1900 and promoter-lux reporters (hrpL, hrpK1, hrpA2, and hopAJ1) were cotransformed into P. savastanoi pv. phaseolicola $\Delta$ hrpL strain. A, Relative activities for hrpK1-lux, B, hrpA2-lux, C, hopAJ1-lux, and D, hrpL-lux. A single colony was cultured in King's B broth until optical density at $600 \mathrm{~nm}=0.6$ and was then transferred into minimal medium. Lux activities were measured over 6 h. Three asterisks $(* * *)$ denote $P<0.001$ compared with empty vector pAK1900, by Student's $t$ test. Each experiment has been performed three times. 
series of $h r p L$ promoter-lux reporters carrying point mutations, insertions, or deletions (G161A, T160C, G159T, C158T, C157A, A156C, A155C, A154C, A153C, 160D, 158D, 159I1, and 159I2) in the $P$. savastanoi pv. phaseolicola wild-type strain. The activities of $l u x$-reporters with G161A, G159T, and C157A were significantly lower than that of the 171-bp wildtype control (20-, 16-, and eightfold, respectively), which demonstrated that they were crucial sites for HrpS binding (Fig. 5P). The hrpL-lux reporters containing insertions or deletions also had significantly lower activities compared with the reporter with wild-type $h r p L$ promoter (fourfold for 160D, 4.3-fold for 159I1, and sixfold for 159I2). In addition, we searched for the newly found HrpS motif in the promoters of $h r p K 1, h r p A 2$,
hopAJl, and $h r p S$ and found similar sequences (Supplementary Fig. S5). In sum, we showed that $161 \mathrm{G}, 159 \mathrm{G}$, and $157 \mathrm{C}$ are crucial sites in the 8-bp motif of HrpS binding.

\section{HrpS directly binds to a group of non-T3SS genes.}

Besides T3SS genes, our ChIP-seq data suggested that HrpS also bound to a group of non-T3SS genes, including the upstream region of PSPPH 1496 (encoding a hypothetical protein), the promoter of PSPPH_3494 (encoding a hypothetical protein), the coding region of PSPPH_3495 (encoding a diguanylate cyclase), the coding region of alaS (encoding alanyl-tRNA synthetase), and the upstream as well as the coding region of PSPPH_1525 (encoding a protein homologous
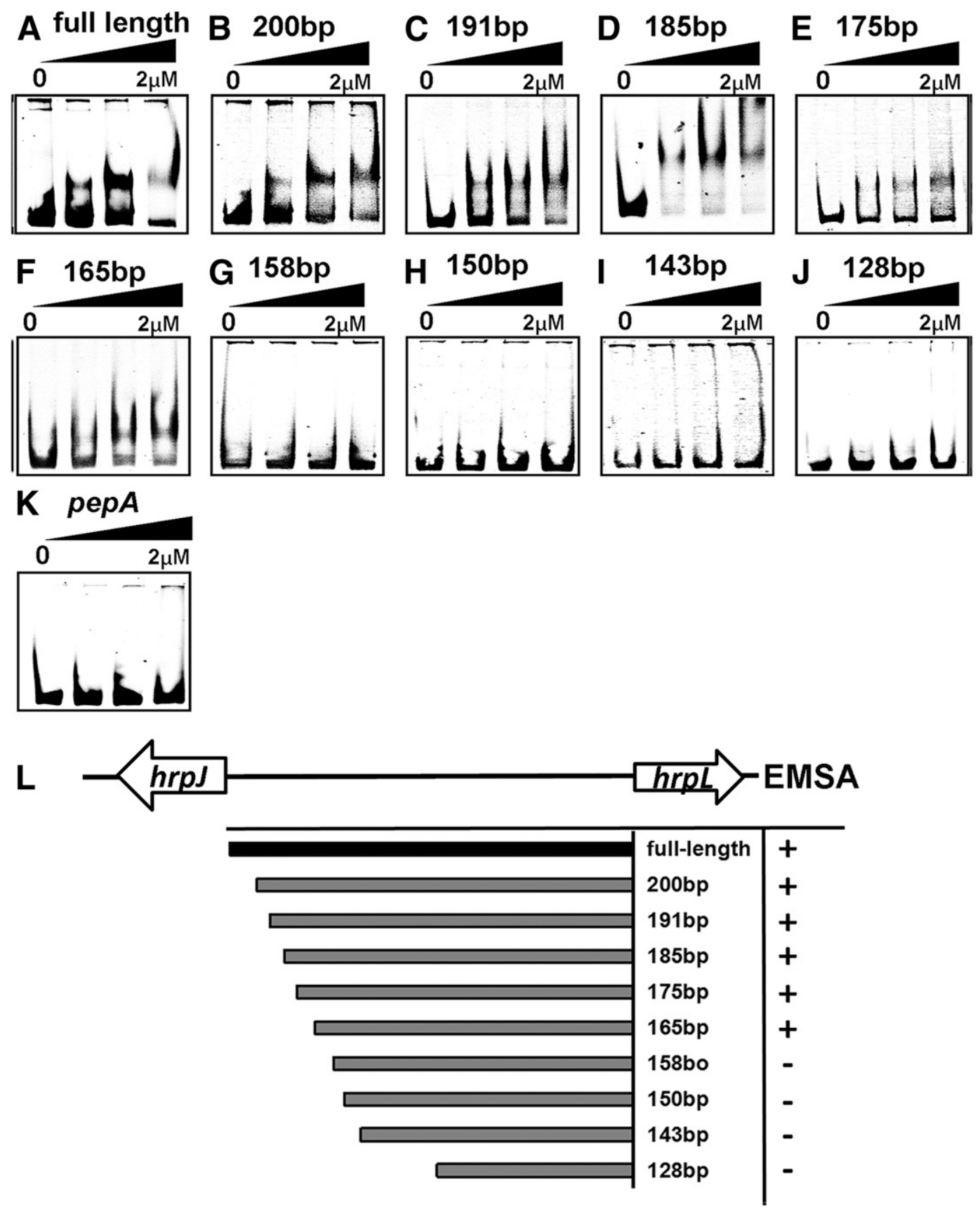

Fig. 4. HrpSC bound to a specific region $(-165$ to $-150 \mathrm{bp})$ in the hrpL promoter. The hrpL promoter was truncated into different lengths (full-length, 242 , 200, $191,185,175,165,158,150,143$, and 128 bp), with the same 3 ' end, before being subjected to electrophoretic mobility shift assay (EMSA) with HrpSC (0, 0.5, 1.0 , and $2.0 \mu \mathrm{M}$ ). A to $\mathbf{F}$, HrpSC showed an obvious binding shift on hrpL promoter truncations longer than $165 \mathrm{bp}$. $\mathbf{G}$ to $\mathbf{J}$, No binding shift when the truncations were shorter than $150 \mathrm{bp}$. K, As the negative control, the pepA promoter had no binding shift with HrpSC. L, Summary of all EMSA (A to J). "+" represents obvious binding shift. "“” represents no binding shift. 
to XopAD). We located potential HrpS-binding motifs in 12 of 25 regions. Subsequently, EMSA showed that $\operatorname{HrpS}^{\mathrm{C}}$ directly bound efficiently to PSPPH_1496 (promoter), PSPPH_3494 (promoter), PSPPH_3495 (open reading frame [ORF]), alaS (ORF), and PSPPH_1525 (promoter) (Figs. 6A-E), compared with the negative controls ribD (Fig. 2B) and pepA (Fig. 4K). In sum, our result demonstrated that HrpS specifically binds to a group of non-T3SS genes, strongly indicating that HrpS alone regulates these genes.

HrpS alone regulates a group of non-T3SS genes.

To investigate if HrpS regulates PSPPH_1496, PSPPH_3494, and PSPPH_1525, the promoter-lux or promoter-ORF-lux reporters were constructed to measure their transcriptional and

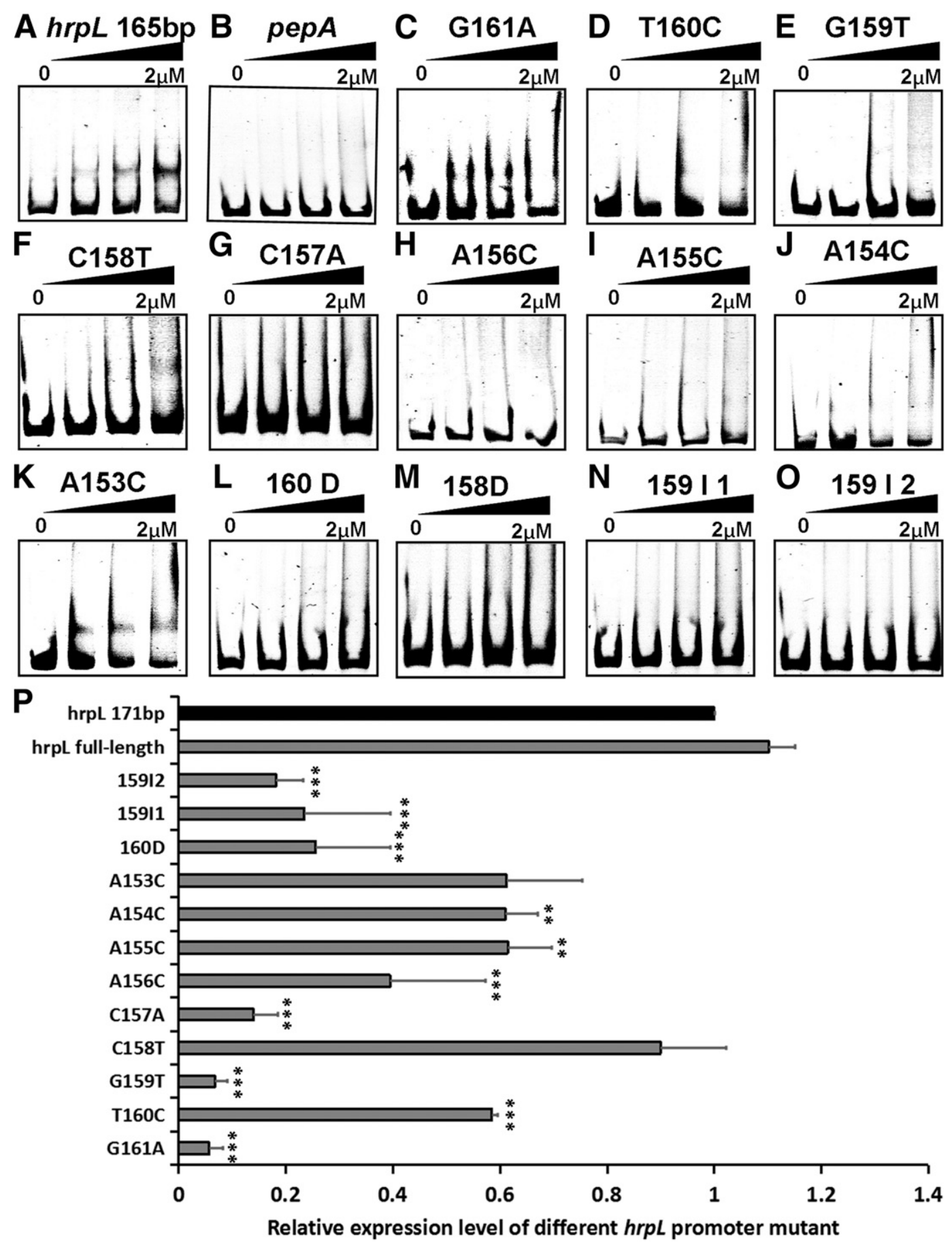

Fig. 5. Electrophoretic mobility shift assay revealed a specific 8-bp HrpS-motif (GTGCCAAA) in the hrpL promoter. HrpSC $(0,0.5,1.0$, and $2.0 \mu M$ ) was mixed with $\mathbf{A}$, the 165 -bp hrpL promoter as the positive control and $\mathbf{B}$, the pepA promoter as the negative control. $\mathbf{C}$ to $\mathbf{J}$, mutants ranging from -161 to $-154 \mathrm{bp}$ (G161A, T160C, G159T, C158T, C157A, A156C, A155C, and A154C). K, A mutant out of the -161 to 154 bp region in the hrpL promoter (A153C). L to O, Mutants carrying deletion or insertion (deletion 160D and 158D, insertion 159I1 and 159I2). Each reaction was performed three times. P, Mutagenesis in the HrpS-binding motif via a hrpL-lux reporter. Activities of hrpL-lux reporters carrying point mutations, insertions, or deletions (G161A, T160C, G159T, C158T, C157A, A156C, A155C, A154C, A153C, 160D, 158D, 159I1, and 159I2) in the P. savastanoi pv. phaseolicola wild-type strain in minimal medium for $6 \mathrm{~h}$. An asterisk (*) denotes statistical significance among these mutants, two asterisks $(* *)$ denote $P<0.01$, and three $(* * *) P<0.001$ compared with the empty vector pAK1900, HrpR, and RphR, by Student's $t$ test, respectively. Each experiment has been performed three times. 
translational levels. First, we cotransformed pAK1900-hrpS and different lux-reporters into the P. savastanoi pv. phaseolicola $\Delta h r p L$ strain. The cotransformation of pAK1900 empty vector and the lux-reporters was used as the negative control. The overexpression of HrpS induced the level of PSPPH_1496lux and PSPPH_3494-lux eight- and fourfold in MM, respectively (Fig. 7A and B). On the contrary, the level of PSPPH_1525-lux displayed a fivefold decrease by HrpS in MM (Fig. 7C). In addition, these reporter strains were also cultured and were tested in KB medium. After $20 \mathrm{~h}$, all these reporters were significantly induced by HrpS in KB (Supplementary Fig. S6). We cotransformed a negative control gntR-lux (gntR encoding the repressor for gluconate utilization system GNT-I) and pAK1900-hrpS/pAK1900 into $\Delta h r p L$. There was no change in the gntR-lux levels between the $\Delta h r p L / p A K 1900-$ $h r p S$ and $\Delta h r p L / p A K 1900$ in MM or KB. We concluded that, in MM, HrpS positively regulated PSPPH_1496 and PSPPH_3494 but negatively regulated PSPPH_1525. However, in KB, HrpS positively regulates all three genes. These results demonstrate that HrpS specifically regulates a group of non-T3SS in $P$. savastanoi pv. phaseolicola, which expands its original regulatory pathway in T3SS. Taken together, our results reveal that HrpS directly regulates PSPPH_1496, PSPPH_3494, and PSPPH_1525. HrpS not only regulates T3SS genes but also a group of non-T3SS genes.

\section{HrpS positively regulates motility}

and negatively regulates biofilm formation.

A recent study showed that Chp8 (PSPTO_2907), which can respond to c-di-GMP and HrpRS, is related to biofilm formation and motility in $P$. savastanoi pv. tomato DC3000 (Engl et al. 2014). Therefore, we tested whether HrpS plays a role in biofilm formation and motility. We detected the motility for wild-type $P$. savastanoi pv. phaseolicola, a $\Delta h r p S$ strain, and its complemented strain ( $\Delta h r p S /$ pAK1900-hrpS) on KB medium $(0.4 \%$ agar $)$ at $28^{\circ} \mathrm{C}$. After 2 days, the $\Delta h r p S$ strain showed a compromised motility compared with the wild-type $P$. savastano pv. phaseolicola (Fig. 8A). Biofilm formation was also measured for these three strains, which were incubated in a 96-well plate at an optical density at $600 \mathrm{~nm}\left(\mathrm{OD}_{600}\right)=0.1$. The $\Delta h r p S$ mutant strain produced more biofilm than did wild type and the complemented strain (Fig. 8B), indicating that HrpS has a negative effect on biofilm formation. As a control, the loss of the $h r p S$ gene

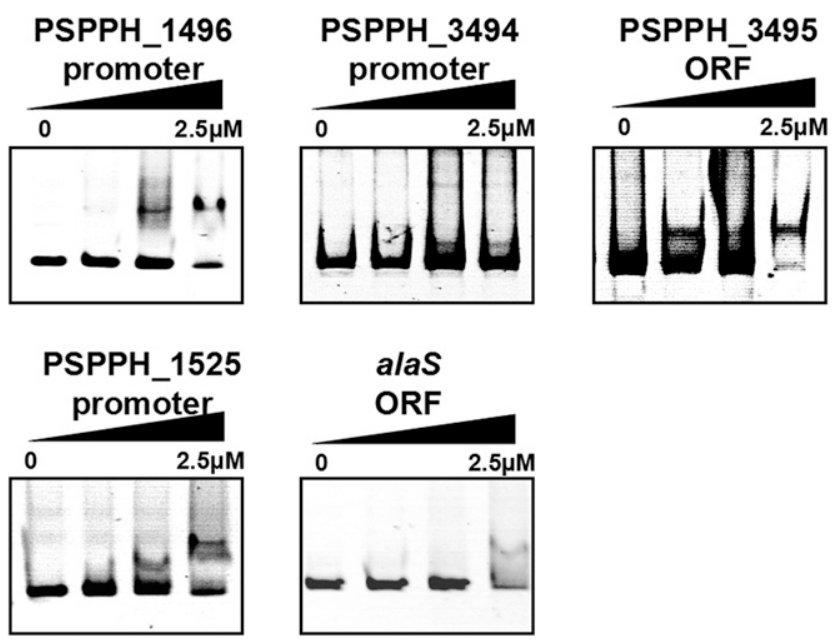

Fig. 6. HrpS directly bound to a group of non-type III secretion system genes. HrpSC $(0,0.5,1.0$, and $2.0 \mu \mathrm{M})$ was mixed with 40-ng probes PSPPH_1496 (promoter), PSPPH_3494 (promoter), PSPPH_3495 (ORF), PSPPH_1525 (promoter), and alaS (ORF [open reading frame]). did not affect the growth rate in $\mathrm{KB}$, compared with the wild-type P. savastanoi pv. phaseolicola (Supplementary Fig S9).

\section{HrpR alone didn't bind to promoters of $h r p K 1, h r p A 2$, and hopAJ1.}

Given that HrpR and HrpS form a hetero-hexamer in the previous report (Lawton et al. 2014), we investigated if HrpR alone can bind to the promoters of three tested T3SS genes. First, the C-terminal DNA binding domain $\mathrm{HrpR}^{\mathrm{C}}$ (amino acids 241 to 306 , homologous to the counterpart in $\operatorname{HrpS}^{\mathrm{C}}$ ) was successfully expressed and was purified by His6x-tag in E. coli BL21 star (DE3). Subsequent EMSA showed that HrpR ${ }^{\mathrm{C}}$ bound to the $h r p L$ promoter and ribD (ORF) (Supplementary Fig. S8) but did not bind to the promoter of $h r p K 1, h r p A 2$, and hopAJ1, because they were absent in the ChIP-seq result of HrpR. In sum, although HrpR directly binds to the $h r p L$ promoter, it cannot bind to the T3SS genes ( $h r p K 1, h r p A 2$, and hopAJl), which suggests the global regulation of HrpS in the P. savastanoi T3SS.

\section{DISCUSSION}

In this study, we provided biochemical and genetic evidence illustrating the molecular mechanism of HrpS in regulating a group of T3SS genes and non-T3SS genes. Our ChIP-seq assays for HrpR, HrpS, and HrpL found that two, 20, and 13 binding peaks were located in the intergenic region, respectively (Fig. 1A, C, and E). These results led us to test if HrpS independently regulates both T3SS and non-T3SS genes. We noticed that a majority of HrpS-binding peaks were located in coding regions of the genome, which is different from the notion that transcription factors mostly bind to promoter regions. We have shown direct binding between $\mathrm{HrpS}$ and two peaks in coding regions (PSPPH_3495 and alaS) (Fig. 6C and E), suggesting that $\mathrm{HrpS}$ has more and complicated regulatory functions in recognizing coding regions. We propose that HrpS directly regulates non-T3SS genes but still relies on HrpR and HrpL to regulate other T3SS genes. Given the limited peaks and low DNA-binding affinity by HrpR, we could not specify the binding site of HrpR in this study. We speculate that HrpR has a different and weak binding site, which might be close to the HrpS motif in the promoter of $h r p L$. HrpS may form a homo-hexamer to regulate gene expression. We propose that the formation of a HrpRS complex facilitates the binding between HrpS and DNA.

HrpL-binding loci have been previously characterized by ChIP-seq assays in P. savastanoi pv. tomato DC3000 (Lam et al. 2014). Here, our ChIP-seq revealed 31 HrpL-binding peaks, including 15 T3SS genes in P. savastanoi pv. phaseolicola. Among these T3SS genes, 12 were found in P. savastanoi pv. tomato DC3000 (Lam et al. 2014). One non-T3SS gene (PSPPH_1855) was shared in ChIP-seq results for HrpS and HrpL. In a previous study, PSPPH_1525 is regulated by HrpL in P. savastanoi pv. phaseolicola (Vencato et al. 2006a). Thirteen new HrpL targets were identified in this study: $c y s S$, PSPPH_2242, PSPPH_2291, PSPPH_2408, PSPPH_2649, nirB, garK, PSPPH_3733, PSPPH_2520, baeS1, dnaE2, PSPPH_2789, and PSPPH_2897 (Supplementary Table S3). Further study needs to be done to test whether HrpL regulates these non-T3SS genes, which may find novel and important roles of HrpL in other cellular processes. In sum, our HrpL ChIP-seq data not only agreed with the previous publication but also revealed new potential $\mathrm{HrpL}$ targets with novel functions.

The DNA-binding motif of HrpS in Erwinia amylovora is a dyad symmetry sequence (TGCAA-N4-TTGCA) (Lee et al. 2016), which is absent in the promoter of hrpL in P. savastanoi. In the present study, we pinpointed the HrpS-binding motif as an 8-bp crucial sequence (GTGCCAAA) from -161 to - 154 bp in the $h r p L$ promoter (Fig. 4). Among this motif, 161G, 159G, 
and $157 \mathrm{C}$ were crucial sites for HrpS binding (Fig. 5). The motif can also be found in the promoters of three new HrpS targets ( $h r p K 1, h r p A 2$, and hopAJ1).

In our previous study, microarray analyses were conducted to identify the gene expression profiles in a $h r p R$ mutant, a $h r p S$ mutant, a hrpL mutant, and the wild-type strain under T3SS- inducing conditions in $P$. savastanoi pv. tomato DC3000 (Lan et al. 2006). Our previous microarray showed that HrpR regulates itself and a group of non-T3SS genes. HrpS controls a large group of T3SS as well as non-T3SS genes. HrpL mainly regulates T3SS genes that largely overlapped with the HrpS regulon. Given that two different strains were used for ChIP-seq

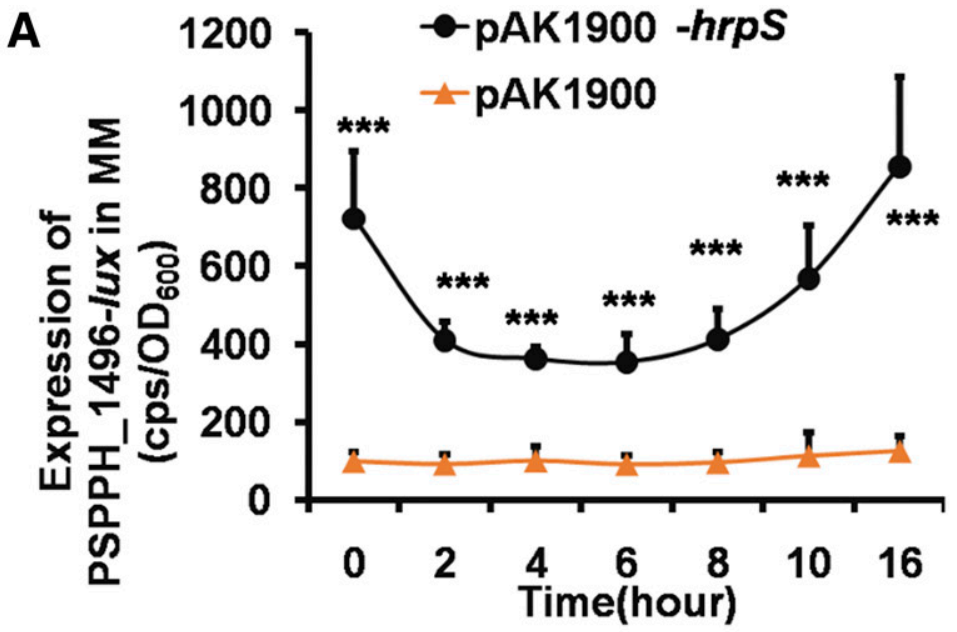

B
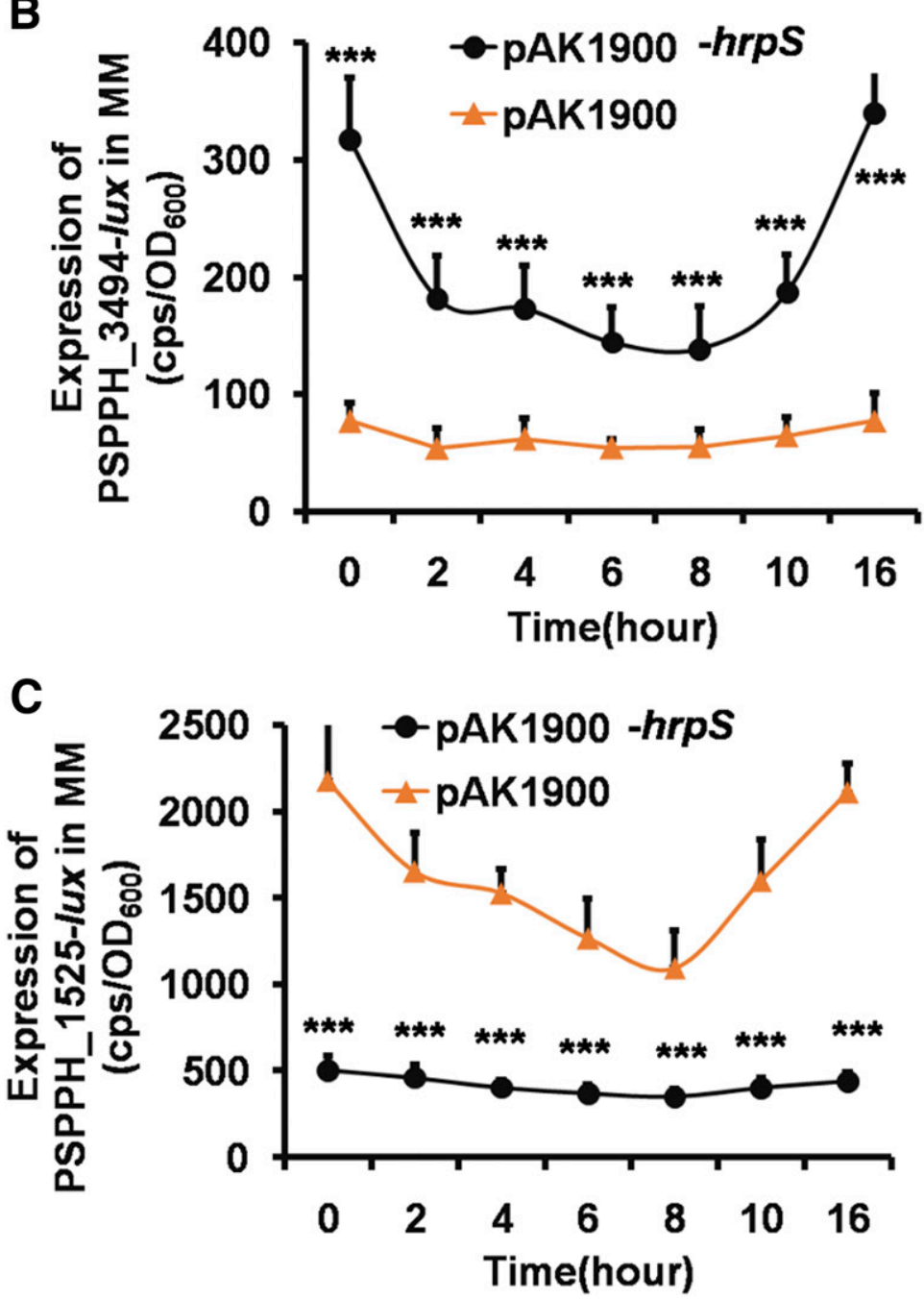

Fig. 7. HrpS regulated a group of non-type III secretion system genes. A, Activities of PSPPH_1496-lux, B, PSPPH_3494-lux, and C, PSPPH_1525-lux in the P. savastanoi pv. phaseolicola $\Delta \mathrm{hrpL}$ strain carrying pAK1900-hrpS or empty pAK1900. Single colonies were cultured in King's B broth until optical density at $600 \mathrm{~nm}=0.6$ and were then transferred into minimal medium. One asterisk $(*)$ denotes $P<0.05$, two $(* *)$ denote $P<0.01$, and three $(* * *) P<0.001$ compared with the empty vector pAK1900, HrpR, and RphR, by Student's $t$ test, respectively. Each experiment has been performed three times. 
(P. savastanoi pv. phaseolicola) and microarray ( $P$. savastanoi pv. tomato DC3000), we first tried to find the corresponding genes between two strains. In microarray data, we found three homologous genes that appeared in ChIP-seq of HrpR, and one of them showed a more than twofold difference. The hrpR microarray data showed that HrpR had a positive regulation on itself. Among 28 genes shared between our ChIP-seq of HrpS and microarray for the hrpS mutant, 15 of the genes showed significant differences compared with the wild-type, including non-T3SS genes PSPTO_0834 (homologous to PSPPH_3759), PSPTO_3087 (homologous to PSPPH_2294), and T3SS genes hopI1, hopAJ1, hrpK1, hrpL, hrpA2 operon, hrcV operon, hrpW1, and hopAA1. Eighty-seven percent of the HrpL ChIPseq binding genes have similar genes in $P$. savastanoi pv. tomato DC3000. Half of these genes were differently expressed in the $h r p L$ mutant compared with the wild type in the microarray, including hrpW1, hrpAl-hrpZ1-hrpB-hrcJ-hrpD-hrpE-HrpF operon ( $h r p A l$ operon), and $h r p J-h r c V$-hrpQ-hrcN-hrpO-hrpPhrcQa-hrcQb-hrcR-hrcS-hrcT-hrcU operon ( $h r p J$ operon), hrpK1, PSPTO_2105 (homologous to PSPPH_1855, encoding thiamine biosynthesis lipoprotein), shcV, hopRl, and hopIl.

In the present study, we found that HrpS directly regulated a group of T3SS and non-T3SS genes for the first time, which made HrpS a global regulator. By using EMSA and $l u x$-reporter assays in $P$. savastanoi, we showed that HrpS directly regulated PSPPH_1496 operon, PSPPH_3494, and PSPPH_1525. In the $\Delta h r p L$ mutant cultured in MM, HrpS functioned as a negative regulator of PSPPH_1525 (Fig. 7D). However, in the $\Delta h r p L$ mutant cultured in $\mathrm{KB}, \mathrm{HrpS}$ is a positive regulator of
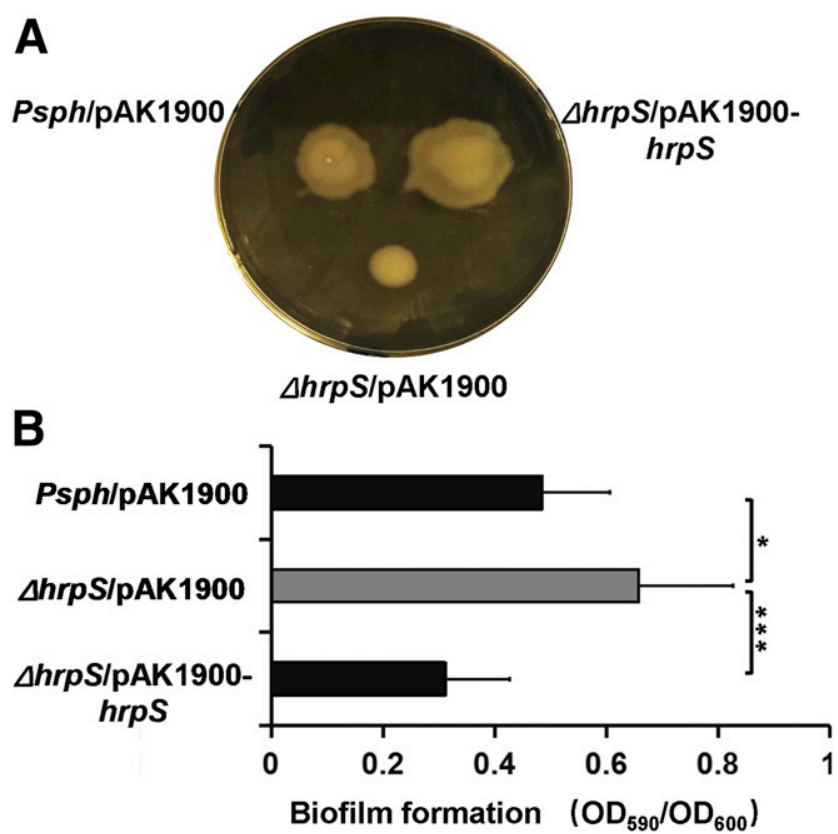

Fig. 8. The effects of HrpS on motility and biofilm formation. A, Motility was observed for the $\Delta$ hrpS complementation strain (pAK1900-hrpS), $\Delta \mathrm{hrpS}$ (pAK1900), and P. savastanoi pv. phaseolicola wild type (pAK1900) grown in King's B medium $\left(0.4 \%\right.$ agar) at $28^{\circ} \mathrm{C}$ for 2 days. B, Biofilm formation was detected among $\triangle \mathrm{hrpS}$ complementation strain (pAK1900hrpS), $\Delta$ hrpS (pAK1900), and $P$. savastanoi pv. phaseolicola wild type (pAK1900). Strains were incubated to an optical density at $600 \mathrm{~nm}\left(\mathrm{OD}_{600}\right)$ $=1.0$ and were then diluted to $\mathrm{OD}_{600}=0.1$ in the 96-well plate. After 3 days of static conditions, the biofilm was stained by $0.1 \%$ crystal violet and measurements were taken at $590 \mathrm{~nm}$ absorbance. The total result was expressed as $\mathrm{OD}_{590} / \mathrm{OD}_{600}$. One asterisk (*) denotes $P<0.05$ and three asterisks (***) denote $P<0.001$ compared with $P$. savastanoi pv. phaseolicola wild type (pAK1900) and $\Delta$ hrpS complementation strain (pAK1900hrpS), by Student's $t$ test.
PSPPH_1525 (Fig. 7H). In addition, HrpS positively regulates PSPPH_1496 in KB and PSPPH_1525 in MM, which indicates that HrpS may sense different environmental signals to exert opposite regulatory roles. We also observed that $\mathrm{HrpS}$ positively regulated motility and negatively tuned biofilm formation in KB but no significant differences occurred in MM. The highly activated T3SS may interfere with motility and biofilm formation. HrpS might have similar binding peaks in $\mathrm{KB}$ as in MM. Taken together, these findings expanded our original understanding of HrpS and suggests possibilities for the study of potential functions of $\mathrm{HrpS}$ on other pathways in the future. Previous study has demonstrated that HrpR alone bound to the hrpL promoter (Jovanovic et al. 2011). Our EMSA verified their binding (Supplementary Fig. S7), although the affinity (dissociation constant $[\mathrm{Kd}]=7 \mu \mathrm{M})$ was lower than that of $\operatorname{HrpS}(\mathrm{Kd}=$ $0.5 \mu \mathrm{M})$. These results might explain the absence of the $h r p L$ promoter in our ChIP-seq data of HrpR. We propose that, although HrpRS mostly function as a hetero-hexamer, they have different individual targets and regulons. HrpS has more important roles than HrpR in regulating their own downstream genes.

Here, we present a new regulatory model of HrpR and HrpS in regulating various T3SS and non-T3SS genes. HrpS induces three T3SS genes ( $h r p K 1, h r p A 2$, and hopAJ1) by directly binding to their promoters, which is independent of HrpL. HrpS also directly activates the expression of non-T3SS genes (PSPPH_1496, PSPPH_1525, and PSPPH_3494) (Fig. 9). In particular, HrpS directly regulates the downstream genes by recognizing a specific 8-bp motif (GTGCCAAAA) in the promoters of $h r p L$ and other downstream genes. HrpR alone has no regulatory role on the $h r p L$ expression. In summary, our study demonstrates that HrpS plays a central role in the T3SS regulatory cascade and activates a group of T3SS as well as non-T3SS genes that bypass HrpL. This work deciphers the key individual roles of HrpS in the regulatory network of T3SS, providing novel insights for developing new strategies to control $P$. savastanoi infection in the future.

\section{MATERIALS AND METHODS}

Bacterial strains and culture condition.

The bacterial strains, plasmids, and primers used are listed in Supplementary Table S4. The P. savastanoi pv. phaseolicola 1448A strains used in this study were the wild-type and the $\Delta$ hrpL mutant. The $P$. savastanoi pv. phaseolicola strains were grown in $\mathrm{KB}$ medium (King et al. 1954) at $28^{\circ} \mathrm{C}$ to $\mathrm{OD}_{600}=2.0$ to 2.5. Then bacteria were centrifuged, were washed twice with $\mathrm{MM}\left(50 \mathrm{mM} \mathrm{KH} \mathrm{PO}_{4}, 7.6 \mathrm{mM}(\mathrm{NH} 4)_{2} \mathrm{SO}_{4}, 1.7 \mathrm{mM} \mathrm{MgCl}\right.$, $1.7 \mathrm{mM} \mathrm{NaCl}$, and $10 \mathrm{mM}$ fructose, pH 6.0) (Huynh et al. 1989; Schumacher et al. 2014), were cultured in MM for $6 \mathrm{~h}$ before further experimentation. Antibiotic concentrations used were: rifampicin, $25 \mu \mathrm{g} / \mathrm{ml}$; kanamycin, $100 \mu \mathrm{g} / \mathrm{ml}$; and carbenicillin, 200 $\mu \mathrm{g} / \mathrm{ml}$. The $E$. coli BL21 (DE3) strain was grown in Luria Bertani (LB) medium at $37^{\circ} \mathrm{C}$ and antibiotics were used at the following concentrations: kanamycin, $50 \mu \mathrm{g} / \mathrm{ml}$ and ampicillin, $50 \mu \mathrm{g} / \mathrm{ml}$.

\section{ChIP-seq.}

ChIP was performed in MM as previously described (Blasco et al. 2012), with minor modifications. An empty pHM2, pHM2- $h r p S_{p s p h}$-FLAG, pHM2- $h r p R_{\mathrm{psph}}$-FLAG, or pHM2$h r p L_{\mathrm{psph}}$-FLAG plasmid was transformed into wild-type $P$. savastanoi pv. phaseolicola and were then cultured in $\mathrm{KB}$ medium until the $\mathrm{OD}_{600}=0.4$ to 0.6 before transferring to $\mathrm{MM}$ liquid medium with spectinomycin $(50 \mu \mathrm{g} / \mathrm{ml})$ for $6 \mathrm{~h}$. The strains were treated with $1 \%$ formaldehyde for $10 \mathrm{~min}$ at $37^{\circ} \mathrm{C}$. Subsequently, $125 \mathrm{mM}$ glycine was added to stop the crosslinking. After centrifugation, bacterial pellets were washed 
twice with Tris buffer $(20 \mathrm{mM}$ Tris- $\mathrm{HCl}, \mathrm{pH} 7.5,150 \mathrm{mM}$ $\mathrm{NaCl})$ and were then resuspended in $500 \mu \mathrm{l}$ IP buffer $(50 \mathrm{mM}$ Hepes-KOH, pH 7.5, $150 \mathrm{mM} \mathrm{NaCl}, 1 \mathrm{mM}$ EDTA, $1 \%$ Triton $\mathrm{X}-100,0.1 \%$ sodium deoxycholate, $0.1 \%$ sodium dodecyl sulfate, mini-protease inhibitor cocktail [Roche]). Next the DNA was sonicated into fragments ranged from 100 to $300 \mathrm{bp}$. The cellular debris was removed, and the supernatant was saved as the input sample in the IP experiments. Both the control and IP samples were washed by protein A beads (General Electric). Then in the IP buffer, the samples were mixed with $50 \mu$ of agarose-conjugated anti-FLAG antibodies (Sigma). The subsequent washing, crosslink reversal, and purification of ChIPDNA was performed following previously reported protocols (Blasco et al. 2012). DNA fragments (150 to $250 \mathrm{bp}$ ) were selected for library construction and sequencing using the NEXTflex ChIP-Seq kit (Bio Scientific). The libraries were sequenced using the HiSeq 2000 system (Illumina). ChIP-seq results were mapped to the $P$. savastanoi pv. phaseolicola genome using TopHat (version 2.0.0) with two mismatches allowed (Trapnell et al. 2009). The binding peaks were detected by MACS software (version 2.0.0) (Zhang et al. 2008); nearly all of them were performed in two experiments and the reported peaks are found in both experiments. All the ChIP-seq data were submitted to NCBI (accession number GSE103921).

\section{Construction of $\Delta h r p L$ and $\Delta h r p S$ mutants.}

To construct the $\Delta h r p L$ and $\Delta h r p S$ mutant, a pAK18mobsacB suicide plasmid was used (Kvitko and Collmer 2011). $h r p L-\mathrm{Up}-\mathrm{F} / \mathrm{R}$ and $h r p S-\mathrm{Up}-\mathrm{F} / \mathrm{R}$ were used to amplify 1-kb fragments upstream of $h r p L$ and $h r p S$ genes, while $h r p L$-Down-F/R and $h r p S$-Down-F/ R were used to amplify $1.5-\mathrm{kb}$ fragments downstream of $h r p L$ and $h r p S$, respectively. First, the purified upstream and downstream fragments of $h r p S$ (using $P s t \mathrm{I}$ ) or $h r p L$ (using $X b a \mathrm{I}$ ) were cut with $P s t \mathrm{I}$ and $X b a \mathrm{I}$, respectively, before being linked by T4 ligase. Second, the linked fragments were cloned to pAK18mobsacB ( $h r p L$ using XbaI/HindIII and hrpS using BamHI/PstI). Next, the constructed vectors were transformed into E. coli S17. After 2 days of mating of the P. savastanoi pv. phaseolicola wild-type strain and the transformed $E$. coli S17 in LM medium (10.0 g of tryptone, $6.0 \mathrm{~g}$ of yeast extract, $0.6 \mathrm{~g}$ of $\mathrm{NaCl}, 0.4 \mathrm{~g}$ of $\mathrm{MgSO}_{4} \cdot 7 \mathrm{H}_{2} \mathrm{O}$, and $1.5 \mathrm{~g}$ of $\mathrm{K}_{2} \mathrm{HPO}_{4}$ in 1 liter), the conjugated strains survived in the $\mathrm{KB}$ plate with rifampin $(25 \mu \mathrm{g} / \mathrm{ml})$ and kanamycin $(100 \mu \mathrm{g} / \mathrm{ml})$. Next, colonies were transferred to $\mathrm{KB}$ plates with kanamycin, rifampin, and $10 \%$ sucrose, to screen for a single-crossover event. Colonies on the sucrose plate were then cultured in both $\mathrm{KB}$ with kanamycin and rifampin and $\mathrm{KB}$ with only rifampin. Loss of kanamycin resistance indicated a double crossover. Finally, the $\Delta h r p L$ and $\Delta h r p S$ mutants were verified by PCR, using primers $h r p L-O R F-$ $\mathrm{F} / \mathrm{R}$ and $h r p S-\mathrm{ORF}-\mathrm{F} / \mathrm{R}$.

\section{Protein expression and purification.}

To express HrpR and HrpS, their coding regions were amplified by PCR ( $h r p R-O R F-F / R$ and $h r p S-O R F-F / R)$, were then digested, and were ligated to pET28a (BamHI/XhoI), which has

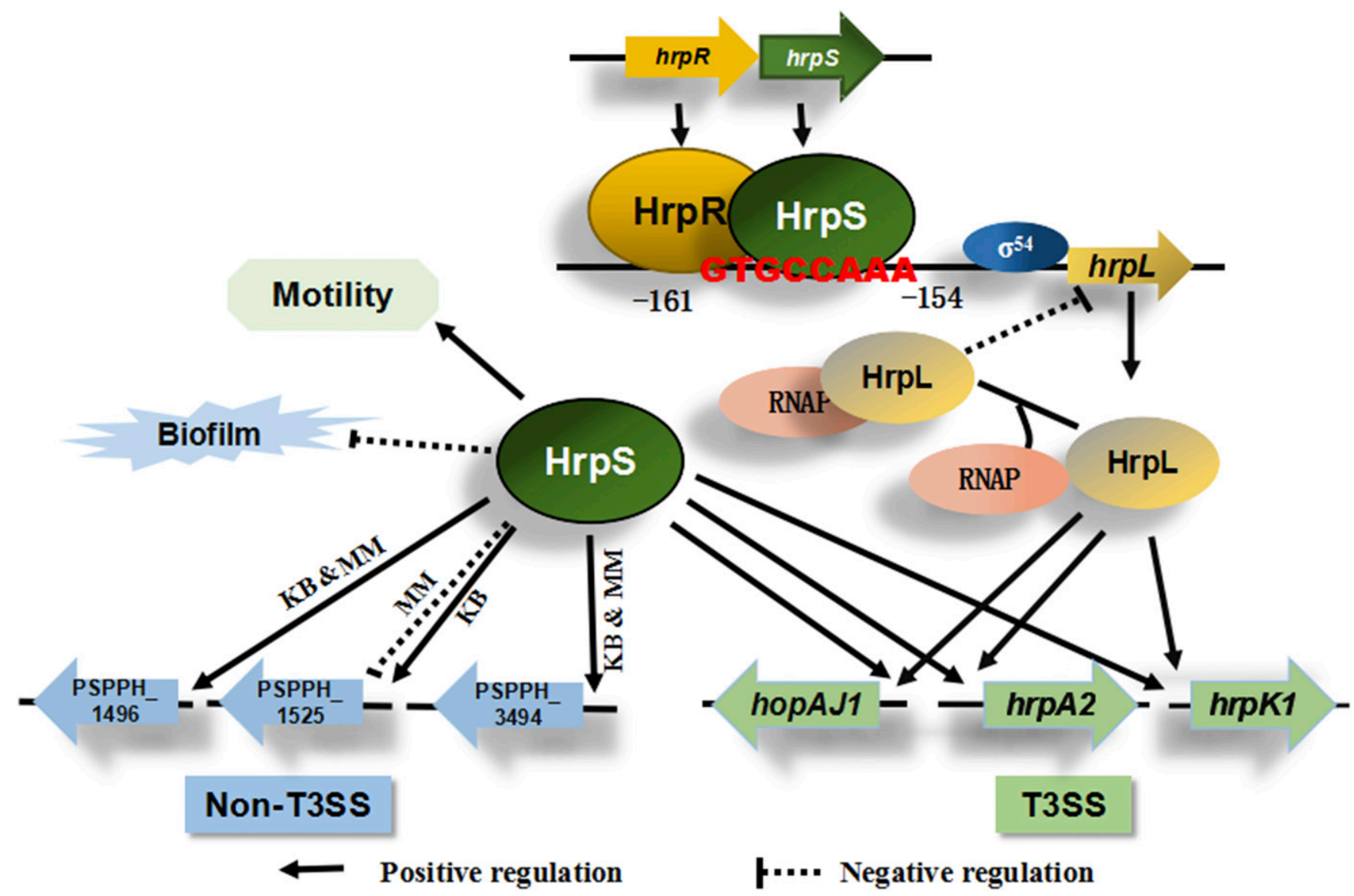

Fig. 9. Proposed models of HrpS-mediated regulation of type III secretion system (T3SS) and non-T3SS genes in Pseudomonas savastanoi. HrpR and HrpS are encoded by the hrpRS operon and form a hetero-hexamer. In T3SS-inducing conditions, HrpS not only activates hrpL but also hrpK1, hrpA2, and hopAJ1, which are also activated by HrpL. HrpL performs self-repression via the HrpL-RNAP complex occupying the HrpRS binding regions. An 8-bp sequence (GTGCCAAA) on the hrpL promoter is essential for HrpS binding. HrpR alone can bind to the hrpL promoter but cannot activate its transcription. HrpS is a global regulator on both T3SS and non-T3SS genes, including PSPPH_1496, PSPPH_1525, and PSPPH_3494. Further, HrpS positively regulates motility but negatively regulates pathways involved in biofilm formation. 
a His6-tag at its N-terminus. To coexpress HrpRS, the hrpRS operon was amplified by PCR (HrpR-ORF-F and HrpS-ORF-R) and was then ligated to pET28a. Although HrpRS had higher activity, it was lower than expected. The C-terminal DNA binding domain of HrpR was truncated from amino acids 241 to 306 aa (nucleotide 721 to $921 \mathrm{bp}$ ), and HrpS was truncated from 235 to 303 aa (nucleotide 703 to $909 \mathrm{bp}$ ). $h r p R_{721-921}$ and $h r p S_{703-909}$ fragments were amplified by PCR, were then digested, and were linked to pET28a (BamHI/XhoI). pET28a-hrpR $R_{721-921}$ and pET28a-hrpS $S_{703-909}$ were then transformed into $E$. coli BL21 star (DE3). Briefly, the selected single colony was cultured in LB liquid overnight, was then transferred to $500 \mathrm{ml}$ of fresh $\mathrm{LB}$ at $37^{\circ} \mathrm{C}$, with shaking. When the $\mathrm{OD}_{600}=0.4$ to $0.6,0.5 \mathrm{mM}$ IPTG (isopropyl $\beta$-D-1-thiogalactopyranoside) was added into the volume to overexpress protein at $16^{\circ} \mathrm{C}$ for $16 \mathrm{~h}$. After centrifugation, strain pellets were resuspended in buffer A $(500 \mathrm{mM} \mathrm{NaCl}$, $25 \mathrm{mM}$ Tris-HCl, pH7.5, 5\% glycerol, $1 \mathrm{mM}$ dithiothreitol [DTT], $1 \mathrm{mM}$ phenyl-methanesulfonyl fluoride). Sonication disrupted cells, which were then centrifuged at $4^{\circ} \mathrm{C}, 12000 \mathrm{rpm}$ for $30 \mathrm{~min}$. The supernatant was filtered through a $0.45-\mu \mathrm{m}$ filter and was mixed with a Ni-NTA column (Qiagen) that had been treated with buffer A. Then the column was washed twice with washing buffer (500 mM NaCl, $25 \mathrm{mM}$ Tris- $\mathrm{HCl}, 60 \mathrm{mM}$ imidazole, $\mathrm{pH7.5,5 \%}$ glycerol, $1 \mathrm{mM}$ DTT, $1 \mathrm{mM}$ phenyl-methanesulfonyl fluoride) and was purified by gradients of 100 to $500 \mathrm{mM}$ imidazole prepared in buffer A. Proteins were concentrated by centrifuge (Millipore) at $4{ }^{\circ} \mathrm{C}$ and were then supplemented with $20 \%$ glycerol and stored at $-80^{\circ} \mathrm{C}$.

\section{EMSA.}

DNA fragments were amplified by PCR. Different concentrations of $\operatorname{HrpS}(0,0.5,1.0$, and $2.0 \mu \mathrm{M})$ and $\operatorname{HrpR}(0,1.6,3.5$, and $7.0 \mu \mathrm{M}$ ) were interacted with $40 \mathrm{ng}$ of purified DNA fragments in a $20-\mu 1$ volume with sample buffer $(10 \mathrm{mM}$ Tris$\mathrm{HCl}$, pH 7.5, $70 \mathrm{mM} \mathrm{KCl}, 5 \mathrm{mM} \mathrm{MgCl}{ }_{2}, 1 \mathrm{mM}$ DTT, $1 \mathrm{mM}$ EDTA, and $10 \%$ glycerol and $0.1 \%$ [wt/vol] Triton X-100) (Jovanovic et al. 2011) at room temperature for $20 \mathrm{~min}$. Free DNA and protein-DNA was divided in $8 \%$ native polyacrylamide gel electrophoresis at $80 \mathrm{~V}$ for $2 \mathrm{~h}$ and the gel was stained by Gel stain (TransGen Biotech) at room temperature and was visualized by the image analysis program (Beijing Liuyi).

\section{Truncation and site mutagenesis assay of $h r p L$ promoter.}

To pinpoint the precise $\mathrm{HrpS}^{\mathrm{c}}$ binding region on the $h r p L$ promoter, it was truncated into 128, 143, 150, 158, 165, 175, 185, 191, and 200 bp (same 3' end at the ATG). Then, an EMSA array was performed, using $\mathrm{HrpS}^{\mathrm{c}}$ and these truncates to identify the binding region. To map the binding regions, $171 \mathrm{bp}$ of $h r p L$ promoter containing single-point mutation (A169C, G165A, T164C, T163C, T162C, G161A, T160C, G159T, C158T, C157A, A156C, A155C, A154C, A153C, deletion 160D, or 158D and insertion 159I1 or 159I2) were designed and linked to the pMS402 (XhoI/BamHI). EMSA was performed to identify the key nucleotides. Using the 165-bp hrpL promoter as positive control, the fragments containing single-point mutation (A169C, G165A, T164C, T163C, T162C, G161A, T160C, G159T, C158T, C157A, A156C, A155C, A154C, A153C, deletion 160D or 158D, and insertion 159I1 or 159I2) were used as probes to bind with $h r p L$ promoter. The corresponding hrpL-lux reporters containing point mutation were transformed into $P$. savastanoi pv. phaseolicola wild type, measuring the luminance using a plate reader in MM.

\section{Luminescence screening assays.}

For lux-reporter fusion, the promoters of $h r p L, h r p K 1$, hrpA2, hopAJ1, PSPPH_1525, PSPPH_1496, or PSPPH_1496 were cloned into the pMS402 plasmid (XhoI/BamHI) (Duan et al.
2003). The lux reporters were transformed into $P$. savastanoi pv. phaseolicola strains. The resulting strains were first cultured to $\mathrm{OD}_{600}=0.6$ in $\mathrm{KB}$. Then the cultures were washed twice with MM medium and were incubated in MM with shaking to measure LUX activities. In addition, the LUX activities for PSPPH_1525, PSPPH_1496, or PSPPH_1496 were also measured in KB, starting at $\mathrm{OD}_{600}=0.01$. Bacterial growth was monitored at the same time by measuring the $\mathrm{OD}_{600}$ in a Synergy 2 plate reader (BioTek). The LUX activity value was acquired by CPS (counts per second)/OD 600 .

\section{RT-qPCR.}

P. savastanoi pv. phaseolicola strains were cultured at $28^{\circ} \mathrm{C}$ in $\mathrm{KB}$ and were then transformed to $\mathrm{MM}$ medium at $\mathrm{OD}_{600}=$ 0.4 to 0.6 . After inducing for $6 \mathrm{~h}$, the bacteria were harvested by centrifugation at $6,000 \mathrm{rpm}$ for $4 \mathrm{~min}$. The RNA was purified by the Purification Kit (Sangon Biotech). The cDNA synthesis was performed by using a cDNA synthesis kit (Takara) with $1.2 \mu \mathrm{g}$ of total RNA in each reaction; $100 \mathrm{ng}$ of each sample was added into each well. Each reaction was performed in triplicate in $20-\mu$ reaction volumes, with $16 \mathrm{~S}$ rRNA as a control. For each reaction, $200 \mathrm{nM}$ primers were used for RT-qPCR. The reactions were run at $37^{\circ} \mathrm{C}$ for $15 \mathrm{~min}, 85^{\circ} \mathrm{C}$, for $5 \mathrm{~s}$, and $4^{\circ} \mathrm{C}$ to save. Next, RT-qPCR was conducted under SYBR Green (Tiangen Biotech) instruction using the ABI 7500 Real-Time PCR System. The reaction includes $15 \mathrm{~min}$ at $95^{\circ} \mathrm{C}$ and 40 cycles of $10 \mathrm{~s}$ at $95^{\circ} \mathrm{C}$ and $32 \mathrm{~s}$ at $60^{\circ} \mathrm{C}$. The fold change represents relative expression level of $\mathrm{mRNA}$ and can be calculated by the values of $2^{-\Delta \Delta \mathrm{Ct}}$.

\section{Swarming motility assay.}

A single colony was grown in KB liquid overnight and was then transferred at $1: 100$ to $2 \mathrm{ml}$ of fresh $\mathrm{KB}$ medium and grown at $28^{\circ} \mathrm{C}$ until $\mathrm{OD}_{600}=0.6$. Two microliters of the cultures were spotted onto soft $\mathrm{KB}$ or MM plates ( $0.4 \%$ agar). The plates were incubated at $28^{\circ} \mathrm{C}$ for $48 \mathrm{~h}$ and swarming across the plate was measured as the diameter of spread. All assays were performed in triplicate.

\section{Biofilm formation assay.}

Biofilm formation was measured as described previously (Engl et al. 2014). Briefly, the $\Delta h r p S$ mutant and wild-type strains were grown in $\mathrm{KB}$ or $\mathrm{MM}$ at $28^{\circ} \mathrm{C}$ to $\mathrm{OD}_{600}=1.0$, were then diluted to $\mathrm{OD}_{600}=0.1$ and $150 \mu \mathrm{l}$ was added to 96 -well plates, and all were incubated at $28^{\circ} \mathrm{C}$ for $72 \mathrm{~h}$ under static conditions. After $72 \mathrm{~h}$ of incubation the $\mathrm{OD}_{600}$ was measured and medium was removed. Biofilm formation in each well was washed gently three times with sterile phosphate buffered saline and was then stained by $150 \mu \mathrm{l}$ of $0.1 \%$ crystal violet and incubated for $20 \mathrm{~min}$. The extra crystal violet was removed and wells were washed gently three times with distilled water. The stained biofilms were resuspended in $150 \mu \mathrm{l}$ of $75 \%$ ethanol and the $\mathrm{OD}_{590}$ was measured for each well. Biofilm formation was expressed as $\mathrm{OD}_{590} / \mathrm{OD}_{600}$. All assays were performed three times.

\section{LITERATURE CITED}

Alfano, J. R., Klm, H. S., Delaney, T. P., and Collmer, A. 1997. Evidence that the Pseudomonas syringae pv. syringae hrp-linked hrmA gene encodes an Avr-like protein that acts in an hrp-dependent manner within tobacco cells. Mol. Plant-Microbe Interact. 10:580-588.

Blasco, B., Chen, J. M., Hartkoorn, R., Sala, C., Uplekar, S., Rougemont, J., Pojer, F., and Cole, S. T. 2012. Virulence regulator EspR of Mycobacterium tuberculosis is a nucleoid-associated protein. PLoS Pathog. 8: e1002621.

Bretz, J., Losada, L., Lisboa, K., and Hutcheson, S. W. 2002. Lon protease functions as a negative regulator of type III protein secretion in Pseudomonas syringae. Mol. Microbiol. 45:397-409. 
Collmer, A., Badel, J. L., Charkowski, A. O., Deng, W. L., Fouts, D. E., Ramos, A. R., Rehm, A. H., Anderson, D. M., Schneewind, O., van Dijk, K., and Alfano, J. R. 2000. Pseudomonas syringae Hrp type III secretion system and effector proteins. Proc. Natl. Acad. Sci. U.S.A. 97:8770-8777.

Deng, X., Lan, L., Xiao, Y., Kennelly, M., Zhou, J. M., and Tang, X. 2010. Pseudomonas syringae two-component response regulator $\mathrm{RhpR}$ regulates promoters carrying an inverted repeat element. Mol. Plant-Microbe Interact. 23:927-939.

Deng, X., Liang, H., Chen, K., He, C., Lan, L., and Tang, X. 2014. Molecular mechanisms of two-component system RhpRS regulating type III secretion system in Pseudomonas syringae. Nucleic Acids Res. 42:11472-11486

Deng, X., Xiao, Y., Lan, L., Zhou, J. M., and Tang, X. 2009. Pseudomonas syringae pv. phaseolicola mutants compromised for type III secretion system gene induction. Mol. Plant-Microbe Interact. 22:964-976.

Duan, K., Dammel, C., Stein, J., Rabin, H., and Surette, M. G. 2003. Modulation of Pseudomonas aeruginosa gene expression by host microflora through interspecies communication. Mol. Microbiol. 50:1477-1491.

Engl, C., Waite, C. J., McKenna, J. F., Bennett, M. H., Hamann, T., and Buck, M. 2014. Chp8, a diguanylate cyclase from Pseudomonas syringae pv. tomato DC3000, suppresses the pathogen-associated molecular pattern flagellin, increases extracellular polysaccharides, and promotes plant immune evasion. MBio 5:e01168-14.

Galán, J. E., and Collmer, A. 1999. Type III secretion machines: Bacterial devices for protein delivery into host cells. Science 284:1322-1328.

Hutcheson, S. W., Bretz, J., Sussan, T., Jin, S., and Pak, K. 2001. Enhancerbinding proteins HrpR and HrpS interact to regulate hrp-encoded type III protein secretion in Pseudomonas syringae strains. J. Bacteriol. 183: 5589-5598.

Huynh, T.V., Dahlbeck, D., and Staskawicz, B.J. 1989. Bacterial blight of soybean: Regulation of a pathogen gene determining host cultivar specificity. Science 245:1374-1377.

Jovanovic, M., James, E. H., Burrows, P. C., Rego, F. G., Buck, M., and Schumacher, J. 2011. Regulation of the co-evolved HrpR and HrpS AAA + proteins required for Pseudomonas syringae pathogenicity. Nat. Commun. 2:177.

Jovanovic, M., Waite, C., James, E., Synn, N., Simpson, T., Kotta-Loizou, I., and Buck, M. 2017. Functional characterization of key residues in regulatory proteins $\mathrm{HrpG}$ and $\mathrm{HrpV}$ of Pseudomonas syringae pv. tomato DC3000. Mol Plant Microbe Interact. 30:656-665.

King, E. E. O., Ward, M. K., and Raney, D. E. 1954. Two simple media for demonstration of pyocyanin and fluorescein. J. Lab. Clin. Med. 44: 301-307.

Kubori, T., Matsushima, Y., Nakamura, D., and Uralil, J., Lara-Tejero, M., Sukhan, A., Galán, J. E., and Aizawa, S.-I. 1998. Supramolecular structure of the Salmonella typhimurium type III protein secretion system. Science 280:602.

Kvitko, B. H., and Collmer, A. 2011. Construction of Pseudomonas syringae pv. tomato DC3000 Mutant and Polymutant Strains. In: Plant Immunity. Methods in Molecular Biology (Methods and Protocols), Vol. 712. J. McDowell, ed. Humana Press, Totowa, NJ, U.S.A.

Lam, H. N., Chakravarthy, S., Wei, H. L., BuiNguyen, H., Stodghill, P. V., Collmer, A., Swingle, B. M., and Cartinhour, S. W. 2014. Global analysis of the HrpL regulon in the plant pathogen Pseudomonas syringae pv. tomato DC3000 reveals new regulon members with diverse functions. PLoS One 9:e106115.

Lan, L., Deng, X., Zhou, J., and Tang, X. 2006. Genome-wide gene expression analysis of Pseudomonas syringae pv. tomato DC3000 reveals overlapping and distinct pathways regulated by $h r p L$ and $h r p R S$. Mol. Plant-Microbe Interact. 19:976-987.

Lawton, E., Jovanovic, M., Joly, N., Waite, C., Zhang, N., Wang, B., Burrows, P., and Buck, M. 2014. Determination of the self-association residues within a homomeric and a heteromeric AAA+ enhancer binding protein. J. Mol. Biol. 426:1692-1710.

Lee, J. H., Sundin, G. W., and Zhao, Y. 2016. Identification of the HrpS binding site in the $h r p L$ promoter and effect of the RpoN binding site of HrpS on the regulation of the type III secretion system in Erwinia amylovora. Mol. Plant Pathol. 17:691-702.
Lindeberg, M., Cartinhour, S., Myers, C. R., Schechter, L. M., Schneider, D. J., and Collmer, A. 2006. Closing the circle on the discovery of genes encoding Hrp regulon members and type III secretion system effectors in the genomes of three model Pseudomonas syringae strains. Mol. PlantMicrobe Interact. 19:1151-1158.

Lindeberg, M., Stavrinides, J., Chang, J. H., Alfano, J. R., Collmer, A., Dangl, J. L., Greenberg, J. T., Mansfield, J. W., and Guttman, D. S. 2005. Proposed guidelines for a unified nomenclature and phylogenetic analysis of type III Hop effector proteins in the plant pathogen Pseudomonas syringae. Mol. Plant-Microbe Interact. 18:275-282.

Morett, E., and Segovia, L. 1993. The sigma 54 bacterial enhancer-binding protein family: Mechanism of action and phylogenetic relationship of their functional domains. J. Bacteriol. 175:6067-6074.

Nissan, G., Manulis, S., Weinthal, D. M., Sessa, G., and Barash, I. 2005. Analysis of promoters recognized by $\mathrm{HrpL}$, an alternative sigma-factor protein from Pantoea agglomerans pv. gypsophilae. Mol. Plant-Microbe Interact. 18:634-643.

Preston, G., Deng, W. L., Huang, H. C., and Collmer, A. 1998. Negative regulation of hrp genes in Pseudomonas syringae by HrpV. J. Bacteriol. 180:4532-4537.

Quiñones, B., Pujol, C. J., and Lindow, S. E. 2004. Regulation of AHL production and its contribution to epiphytic fitness in Pseudomonas syringae. Mol. Plant-Microbe Interact. 17:521-531.

Roine, E., Wei, W., Yuan, J., Nurmiaho-Lassila, E. L., Kalkkinen, N., Romantschuk, M., and He, S. Y. 1997. Hrp pilus: An hrp-dependent bacterial surface appendage produced by Pseudomonas syringae pv. tomato DC3000. Proc. Natl. Acad. Sci. U.S.A. 94:3459-3464.

Schumacher, J., Joly, N., Rappas, M., Zhang, X., and Buck, M. 2006. Structures and organisation of AAA+ enhancer binding proteins in transcriptional activation. J. Struct. Biol. 156:190-199.

Schumacher, J., Waite, C. J., Bennett, M. H., Perez, M. F., Shethi, K., and Buck, M. 2014. Differential secretome analysis of Pseudomonas syringae pv. tomato using gel-free MS proteomics. Front. Plant Sci. 5:242.

Trapnell, C., Pachter, L., and Salzberg, S. L. 2009. TopHat: Discovering splice junctions with RNA-Seq. Bioinformatics 25:1105-1111.

Vencato, M., Tian, F., Alfano, J. R., Buell, C. R., Cartinhour, S., DeClerck, G. A., Guttman, D. S., Stavrinides, J., Joardar, V., Lindeberg, M. Bronstein, P. A., Mansfield, J. W., Myers, C. R., Collmer, A., and Schneider, D. J. 2006a. Bioinformatics-enabled identification of the HrpL regulon and type III secretion system effector proteins of Pseudomonas syringae pv. phaseolicola 1448A. Mol. Plant-Microbe Interact. 19:1193-1206.

Vencato, M., Tian, F., Alfano, J. R., Buell, C. R., Cartinhour, S., DeClerck, G. A., Guttman, D. S., Stavrinides, J., Joardar, V., Lindeberg, M., Bronstein, P. A., Mansfield, J. W., Myers, C. R., Collmer, A., and Schneider, D. J. 2006b. Bioinformatics-enabled identification of the HrpL regulon and type III secretion system effector proteins of Pseudomonas syringae pv. phaseolicola 1448A. Mol. Plant-Microbe Interact. 19:1193-1206

Waite, C., Schumacher, J., Jovanovic, M., Bennett, M., and Buck, M. 2017. Negative autogenous control of the master type III secretion system regulator HrpL in Pseudomonas syringae. MBio 8:e2273-16.

Wei, C. F., Deng, W. L., and Huang, H. C. 2005. A chaperone-like HrpG protein acts as a suppressor of $\mathrm{HrpV}$ in regulation of the Pseudomonas syringae pv. syringae type III secretion system. Mol. Microbiol. 57:520-536.

Xiao, Y., Heu, S., Yi, J., Lu, Y., and Hutcheson, S. W. 1994. Identification of a putative alternate sigma factor and characterization of a multicomponent regulatory cascade controlling the expression of Pseudomonas syringae pv. syringae Pss61 hrp and hrmA genes. J. Bacteriol. 176: 1025-1036.

Xiao, Y., Lan, L., Yin, C., Deng, X., Baker, D., Zhou, J. M., and Tang, X. 2007. Two-component sensor RhpS promotes induction of Pseudomonas syringae type III secretion system by repressing negative regulator RhpR. Mol. Plant-Microbe Interact. 20:223-234.

Zhang, Y., Liu, T., Meyer, C. A., Eeckhoute, J., Johnson, D. S., Bernstein, B. E., Nusbaum, C., Myers, R. M., Brown, M., Li, W., and Liu, X. S. 2008. Model-based analysis of ChIP-Seq (MACS). Genome Biol. 9 R137. 